\title{
Use of computed tomography and automated software for quantitative analysis of the vasculature of patients with pulmonary hypertension
}

\author{
Análise quantitativa por tomografia computadorizada da vasculatura pulmonar em pacientes \\ com hipertensão pulmonar utilizando programa automático
}

\author{
Danilo Tadao Wada ${ }^{1}$, Adriana Ignácio de Pádua ${ }^{2}$, Moyses Oliveira Lima Filho ${ }^{3}$, José Antonio Marin Neto ${ }^{4}$, \\ Jorge Elias Júnior ${ }^{4}$, José Baddini-Martinez ${ }^{4}$, Marcel Koenigkam Santos ${ }^{5}$
}

Wada DT, Pádua Al, Lima Filho MO, Marin Neto JA, Elias Júnior J, Martinez JB, Koenigkam-Santos M. Use of computed tomography and automated software for quantitative analysis of the vasculature of patients with pulmonary hypertension. Radiol Bras. 2017 Nov/Dez;50(6):351-358.

Abstract Objective: To perform a quantitative analysis of the lung parenchyma and pulmonary vasculature of patients with pulmonary hypertension (PH) on computed tomography angiography (CTA) images, using automated software.

Materials and Methods: We retrospectively analyzed the CTA findings and clinical records of 45 patients with PH (17 males and 28 females), in comparison with a control group of 20 healthy individuals ( 7 males and 13 females); the mean age differed significantly between the two groups ( $53 \pm 14.7$ vs. $35 \pm 9.6$ years; $p=0.0001$ ).

Results: The automated analysis showed that, in comparison with the controls, the patients with PH showed lower 10th percentile values for lung density, higher vascular volumes in the right upper lung lobe, and higher vascular volume ratios between the upper and lower lobes. In our quantitative analysis, we found no differences among the various PH subgroups. We inferred that a difference in the 10th percentile values indicates areas of hypovolemia in patients with $\mathrm{PH}$ and that a difference in pulmonary vascular volumes indicates redistribution of the pulmonary vasculature and an increase in pulmonary vasculature resistance.

Conclusion: Automated analysis of pulmonary vessels on CTA images revealed alterations and could represent an objective diagnostic tool for the evaluation of patients with $\mathrm{PH}$.

Keywords: Hypertension, pulmonary; Tomography, X-ray computed; Image processing, computer-assisted.

Resumo Objetivo: Avaliar, quantitativamente, as alterações do parênquima e da vasculatura pulmonar em exames de angiotomografia computadorizada (angio-TC) de pacientes com hipertensão pulmonar (HP), utilizando programa de análise totalmente automática. Materiais e Métodos: Avaliamos, retrospectivamente, prontuários e exames de angio-TC de 45 pacientes com HP (28 mulheres e 17 homens; idade de $53 \pm 14,7$ anos), em comparação com um grupo controle mais jovem sem comorbidades detectadas (13 mulheres e 7 homens; idade de $35 \pm 9,6$ anos). Os grupos diferiram estatisticamente quanto à idade $(p=0,0001)$.

Resultados: Análise automática mostrou valores menores do percentil 10 da densidade dos pulmões, maior volume vascular do lobo superior direito e volume vascular relativo entre lobos superiores e inferiores nos pacientes com HP, quando comparados com o grupo controle. Não encontramos diferenças da análise quantitativa por angio-TC entre grupos de pacientes com HP. Inferimos que a diferença nos valores do percentil 10 indique a presença das áreas de oligoemia nos pacientes com HP, enquanto as diferenças nos volumes vasculares indiquem redistribuição da trama e aumento da resistência vascular pulmonar.

Conclusão: A análise quantitativa automática da vasculatura pulmonar em imagens de angio-TC identificou alterações e pode representar ferramenta diagnóstica objetiva na avaliação da HP.

Unitermos: Hipertensão pulmonar; Tomografia computadorizada; Processamento de imagem assistida por computador.

Study conducted at the Centro de Ciências das Imagens e Física Médica (CCIFM) of the Hospital das Clínicas da Faculdade de Medicina de Ribeirão Preto da Universidade de São Paulo (HCFMRP-USP), Ribeirão Preto, SP, Brazil.

1. MSc, Attending Physician at the Centro de Ciências das Imagens e Física Médica (CCIFM) of the Hospital das Clínicas da Faculdade de Medicina de Ribeirão Preto da Universidade de São Paulo (HCFMRP-USP), Ribeirão Preto, SP, Brazil.

2. PhD, Attending Physician in the Pulmonology Department of the Hospital das Clínicas da Faculdade de Medicina de Ribeirão Preto da Universidade de São Paulo (HCFMRP-USP), Ribeirão Preto, SP, Brazil.

3. PhD, Attending Physician in the Cardiology Department of the Hospital das Clínicas da Faculdade de Medicina de Ribeirão Preto da Universidade de São Paulo (HCFMRP-USP), Ribeirão Preto, SP, Brazil.

4. PhD, Professor in the Department of Internal Medicine of the Hospital das Clínicas da Faculdade de Medicina de Ribeirão Preto da Universidade de São Paulo (HCFMRP-USP), Ribeirão Preto, SP, Brazil.

\section{INTRODUCTION}

Pulmonary hypertension (PH) is a chronic clinical disease characterized by elevated pulmonary vascular resistance and pressure associated with extensive vascular

5. PhD, Collaborating Professor in the Department of Internal Medicine of the Hospital das Clínicas da Faculdade de Medicina de Ribeirão Preto da Universidade de São Paulo (HCFMRP-USP), Ribeirão Preto, SP, Brazil.

Mailing address: Dr. Danilo Tadao Wada. HCFMRP-USP. Avenida Bandeirantes, 3900, Campus Universitário, Monte Alegre. Ribeirão Preto, SP, Brazil, 14048-900. E-mail: danilowada@yahoo.com.br.

Received September 6, 2016. Accepted after revision November 29, 2016. 
proliferation and remodeling. It is defined as a mean pulmonary artery pressure (mPAP) greater than or equal to 25 $\mathrm{mmHg}$ at rest or greater than $30 \mathrm{mmHg}$ during exercise ${ }^{(1)}$, as determined by right heart catheterization (RHC). The $\mathrm{PH}$ classification most widely used in clinical practice is the 2013 Nice classification system ${ }^{(1-3)}$ : group 1 comprises forms of pulmonary arterial hypertension, including idiopathic forms; group 2 comprises forms of $\mathrm{PH}$ secondary to disease of the left heart; group 3 comprises forms of PH secondary to chronic lung parenchyma disease or chronic hypoxia; group 4 comprises forms of $\mathrm{PH}$ secondary to chronic thromboembolism; and group 5 comprises forms of PH secondary to poorly understood multifactorial mechanisms.

Despite the advances in noninvasive imaging methods, RHC with mPAP measurement remains the gold standard for the diagnosis of PH. Despite the low risk of adverse events, catheterization is an invasive diagnostic method and should not be performed without an appropriate indication ${ }^{(4)}$. Various methods and tools have been used in attempts to find a replacement for catheterization in the diagnosis of $\mathrm{PH}$ or to reduce the number of indications for $\mathrm{RHC}^{(5-8)}$. However, only a few of those methods have been incorporated in the clinical routine for the evaluation of patients with $\mathrm{PH}$, one such method being computed tomography (CT) of the chest, especially CT angiography (CTA) of the pulmonary arteries.

New tools for quantitative and functional evaluation have been used in imaging studies to increase the diagnostic capacity of the methods, as well as to provide information that is more objective and has prognostic value. Computerized quantitative analysis of chest CT images has been used in the evaluation of various lung diseases, mainly emphysema, as well as airway diseases (such as asthma and cystic fibrosis) and interstitial lung diseases. The method has been used in order to describe the natural progression of the diseases, assess severity, stratify the prognostic risk, and monitor the treatment, showing a good correlation with the pathological findings and functional test results ${ }^{(9-11)}$.

The objective of this study was to perform a quantitative analysis of the parenchyma and pulmonary vasculature on CTA images of patients diagnosed with PH by RHC. To that end, we used a computer program with fully automated analysis capability.

\section{MATERIALS AND METHODS}

\section{Patients}

This study was approved by the Research Ethics Committee of the Hospital das Clínicas da Faculdade de Medicina de Ribeirão Preto da Universidade de São Paulo (HCFMRP-USP). Because it was a retrospective study based on examinations already performed by patients with a clinical indication for the follow-up/evaluation of $\mathrm{PH}$, the need for informed consent was waived.
We retrospectively assessed the physical, electronic, and CTA records of adult patients with $\mathrm{PH}$ in clinical follow-up at our reference hospital. The RHC and CT examinations were requested as part of the routine clinical evaluation of these patients, there being no description of investigation of infection or suspicion of another acute complication. We included patients who had undergone CTA at our facility on the same devices and with confirmation by RHC with mPAP measurement. Patients for whom the technical quality of the tests was considered inadequate for diagnosis and quantitative analysis were excluded. After we applied the selection criteria, the sample comprised 45 patients with PH (Figure 1).

The control group comprised 20 examinations of young patients submitted to CTA for investigation of acute pulmonary thromboembolism, with a negative result, without other clinical or laboratory signs of pulmonary thromboembolism or other pulmonary vascular disease. In this group, we excluded individuals with radiological or clinical signs of diffuse lung disease, focal lesions greater than $3.0 \mathrm{~cm}$, heart disease, or other significant changes detectable by CTA.

\section{CT of the chest}

CT scans were performed on multidetector devices with inspiratory volumetric images obtained after intravenous administration of iodinated contrast medium in a single bolus injection followed by a saline flush. Other typical parameters are as follows: slice thickness $\leq 2 \mathrm{~mm}$; reconstruction interval $\leq 1 \mathrm{~mm}$; voltage, $120 \mathrm{kVp}$; current, $150-200 \mathrm{mAs}$; gantry rotation, $0.3-0.7 \mathrm{~s}$. The volumetric acquisitions were reconstructed with soft and hard filters, with windows for the mediastinum and lung, and analyzed on a dedicated workstation.

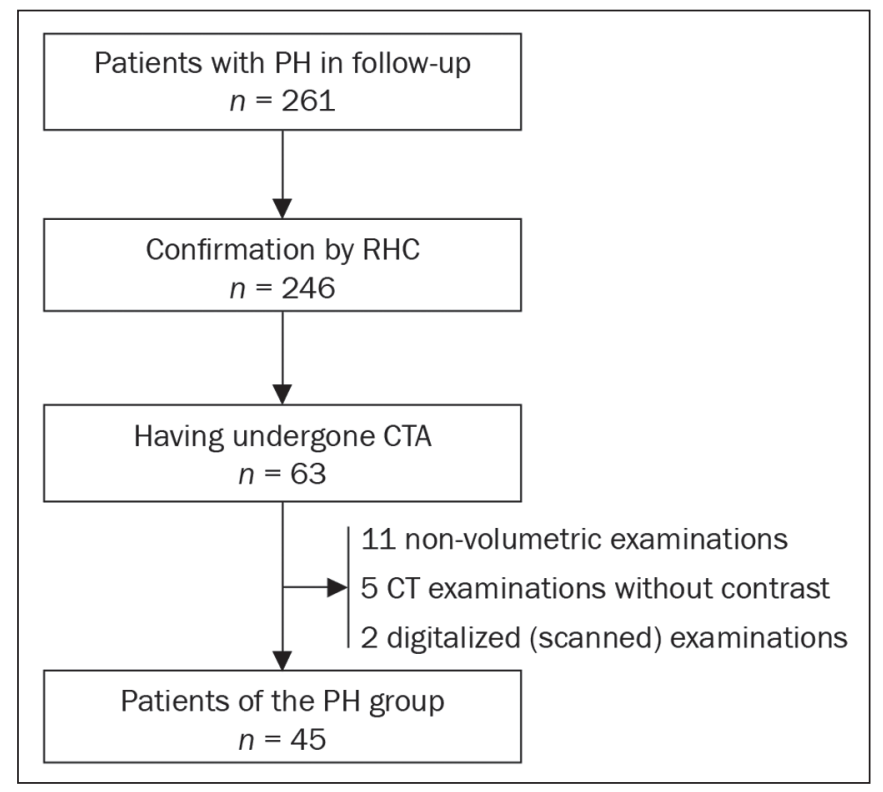

Figure 1. Algorithm of the inclusion and exclusion criteria applied in the selection of the PH group patients. 


\section{Qualitative evaluation by CT}

We evaluated the examinations qualitatively with the Horos free image viewer, version 1.1.6 for Macintosh, obtaining the measurements of the pulmonary trunk and ascending aorta, as well as the pulmonary trunk/ascending aorta ratio. We also evaluated dilation/dilatation or hypertrophy of the right ventricle, contrast medium reflux into the hepatic veins, attenuation of the lung parenchyma (homogeneous, mosaic, or ground-glass centrilobular nodules), and pulmonary opacities resulting from infarction (bands, streaks, consolidations, and others).

\section{Quantitative analysis}

Quantitative analysis of CT images was performed with the academic program Yacta, version $2.6^{(12)}$. The Yacta program was developed by a group of researchers affiliated with the University of Heidelberg, in Germany, and is used at HCFMRP-USP thanks to a research partnership between the two institutions.

The Yacta program works completely automatically, requiring no user intervention at any stage of the process (Figure 2). The analysis of the images takes 4-9 min after they have been sent for processing. Initially, Yacta segments (anatomically separates) the airways, blood vessels, lungs, and lung lobes; it then supplies the lung volumes and densities, together with the volume of blood vessels in each lung lobe. The program uses an attenuation coefficient of $-500 \mathrm{HU}$ as the standard threshold for the detection of vessels and then segments them according to the lobar division already performed for the airways. In

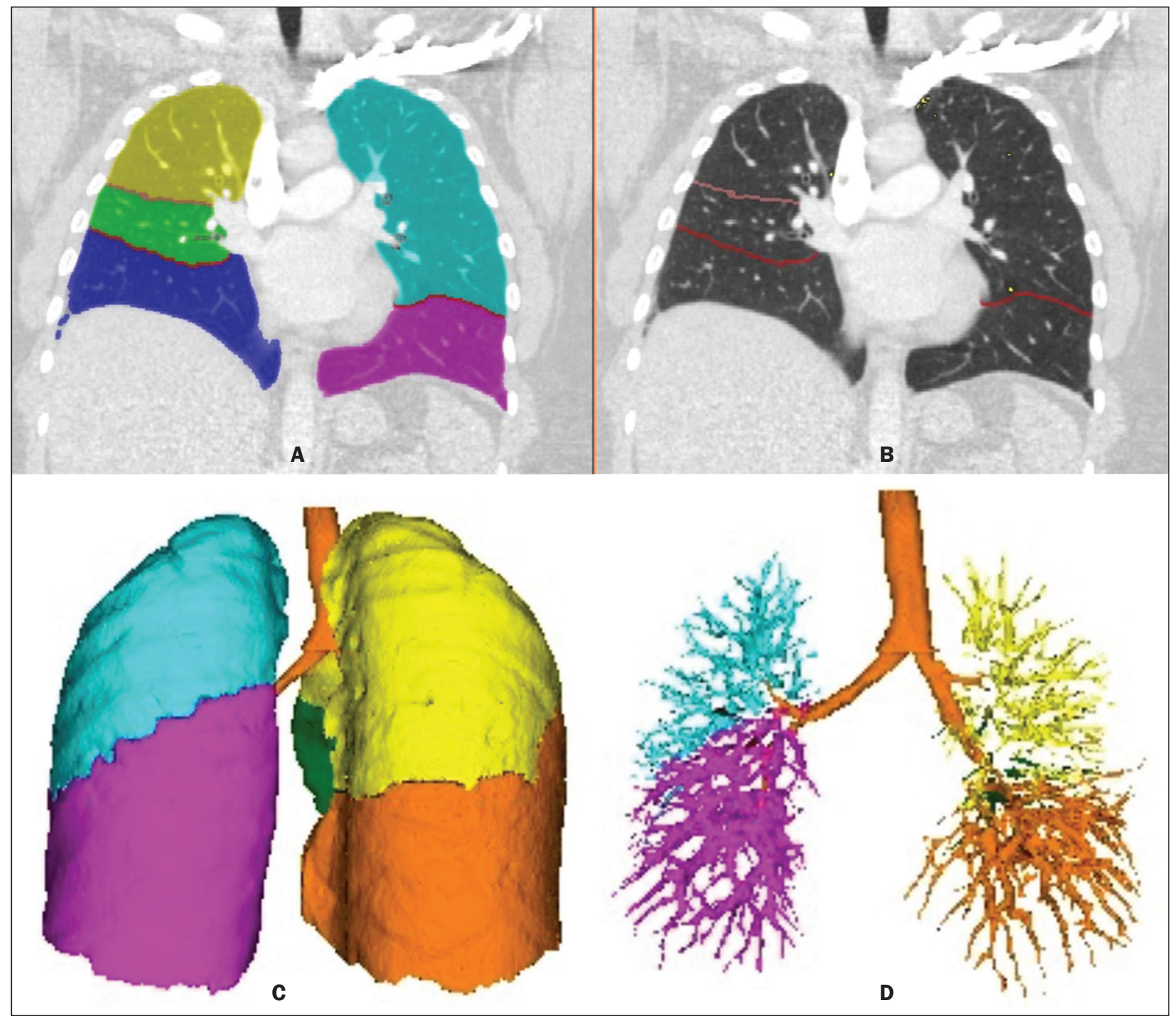

Figure 2. Illustrative reconstructions of the automated pulmonary segmentation performed by the Yacta automated program. A: Coronal reconstruction of the lung, each lung lobe represented by a different color (yellow = RUL, green = middle lobe, dark blue = RLL, light blue = LUL, and pink = LLL). B: Coronal reconstruction with pulmonary fissures delimited by red lines and pulmonary emphysema detected represented by yellow color pixels. C: Volumetric rendering image illustrating the trachea and each lung lobe segmented by the program. D: Volumetric rendering of the airways and pulmonary vasculature of each segmented lobe. 
lungs with an altered attenuation coefficient, the program calculates a new threshold on the basis of an attenuation coefficient histogram. Intrapulmonary voxels with coefficients above the calculated threshold are then labeled as vessels, and vessels with three-dimensional communication larger than $100 \mathrm{~mm}^{3}$ are counted. Smaller voxels are rejected. The value obtained is then multiplied by a correction factor related to the body size of the individual. In addition to the lung volumes and mean densities, the program provides the relative values of lung parenchyma density, including the percentiles. In this study, we arbitrarily selected the 10th percentile (p10) of lung densities in an attempt to differentiate between the $\mathrm{PH}$ and control patients, in analogy to the correlation shown in quantitative studies of emphysema with the 15 th percentile $(\mathrm{p} 15)^{(13)}$.

\section{Statistical analysis}

All data were organized and analyzed on a personal computer, with the spreadsheet program Microsoft Excel 2011 and the statistical analysis program Medcalc, version 9.4 (MedCalc Software, Mariakerke, Belgium). The Shapiro-Wilk test of normality was used in order to verify the normal distribution of the variables. Unpaired $t$-tests were used for comparison between the $\mathrm{PH}$ and control patients, as well as between $\mathrm{PH}$ subgroups 1 and 4 , with a significance level of $95 \%(p<0.05)$. For the most significant variables, we also evaluated the receiver operating characteristic (ROC) curve for the $\mathrm{PH}$ diagnostic test and the Pearson correlation index for the correlation with the mPAP values.

\section{RESULTS}

We evaluated 45 patients with PH (28 females and 17 males; mean age, $53 \pm 14.7$ years) and 20 control subjects (13 females and 7 males; mean age, $35 \pm 9.6$ years). Patients with PH were also divided according to the Nice classification: subgroup $1(n=24)$; subgroup $2(n=2)$; subgroup $3(n=2)$; and subgroup $4(n=17)$. Subgroup 1 was composed of 20 females and 4 males, with a mean age of $44 \pm 16$ years, whereas subgroup 4 was composed of 11 females and 6 males, with a mean age of $54 \pm 10$ years. . The mean age was significantly higher in subgroup 4 than in subgroup $1(p=0.025)$.

We found no significant differences between the $\mathrm{PH}$ and control patients in terms of the mean pulmonary vol- umes and densities. However, the quantitative CT analysis of the lung parenchyma showed a significant difference in the p10 for lung density, the values being lower in the $\mathrm{PH}$ patients (Table 1 and Figure 3).

There was no significant difference between the PH and control patients in terms of the total pulmonary vascular volume, although the vascular volume of the right upper lobe (RUL) was higher in the PH patients than in the control patients. This difference was not significant for the left upper lobe (LUL) or for the right and left lower lobes (RLL and LLL, respectively). In the analysis of the relative vascular volume values, considering the ratio between the upper and lower lobes (ULs/LLs), we found higher values in the $\mathrm{PH}$ patients than in the control patients $(p=0.0006)$, as well as for the RUL/RLL and LUL/ LLL ratios (Table 2 and Figure 4). In the PH patients, the vascular volume was $17 \%$ higher in the upper lobes than in the lower lobes (ULs/LLs ratio, 1.17). In the control patients, the vascular volume in the upper lobes was only $54 \%$ of that obtained for the lower lobes (ULs/LLs ratio, $0.54)$.

In the quantitative CT analysis, we found no significant difference between the two largest subgroups of $\mathrm{PH}$ patients (subgroup 1 and subgroup 4).

For the variable with the most significant difference between the $\mathrm{PH}$ patients and the control patients-the ULs/LLs ratio-we analyzed the ROC curve. This analysis showed an area under the curve of 0.753 , the most accurate cut-off ULs/LLs ratio being 0.64 (64\%), with a sensitivity of $67.4 \%$ and a specificity of $84.1 \%$ (Figure 5 ). Using the Pearson correlation index, we found no significant correlation between the quantitative CT variables and the mPAP values $(\rho<0.3)$, even for the measures that presented the most significant difference in comparison with the control group values.

The data obtained in the qualitative analysis of the $\mathrm{PH}$ patients were consistent with data in the literature. The most common finding was dilatation of the pulmonary trunk with simultaneous dilatation of the segmental arteries and right ventricle, which was seen in $95 \%$ of the patients, followed by contrast medium reflux into the hepatic veins, seen in $70 \%$, right ventricular hypertrophy, seen in $60 \%$, and mosaic attenuation of the lung parenchyma, seen in $45 \%$. Ground-glass centrilobular nodules were seen in $13 \%$ of the $\mathrm{PH}$ patients $(n=6 ; 5$ in subgroup 1$)$.

Table 1-Main parameters of automated quantitative analysis performed on CTA images of PH patients and control patients, as well of the patients in the most important PH subgroups (subgroup 1 - pulmonary arterial hypertension; subgroup 4 - chronic thromboembolism).

\begin{tabular}{|c|c|c|c|c|c|}
\hline Group & $\begin{array}{l}\text { Pulmonary volume } \\
\qquad\left(\mathrm{cm}^{3}\right)\end{array}$ & $\begin{array}{l}\text { Pulmonary density } \\
\qquad(\mathrm{HU})\end{array}$ & $\begin{array}{l}\text { p10 for pulmonary density } \\
\text { (HU) }\end{array}$ & $\begin{array}{l}\text { Pulmonary vascular volume } \\
\qquad\left(\mathrm{cm}^{3}\right)\end{array}$ & $\begin{array}{l}\text { Vascular density } \\
\qquad\left(\times 10^{-3}\right)\end{array}$ \\
\hline Control & $2,987 \pm 741$ & $-652 \pm 78$ & $-799 \pm 59$ & $86 \pm 21$ & $29.7 \pm 6.4$ \\
\hline $\mathrm{PH}$ & $3,067 \pm 1,142$ & $-668 \pm 85$ & $-829 \pm 54 *$ & $90 \pm 31$ & $29.9 \pm 6.9$ \\
\hline Subgroup 1 & $3,042 \pm 1,382$ & $-667 \pm 85$ & $-824 \pm 64$ & $85 \pm 35$ & $29.3 \pm 8.0$ \\
\hline Subgroup 4 & $3,232 \pm 723$ & $-680 \pm 39$ & $-840 \pm 32$ & $95 \pm 15$ & $28.77 \pm 3.7$ \\
\hline
\end{tabular}

p10, 10th percentile; Vascular density = vascular volume / pulmonary volume. * Statistically different $(p<0.05)$. 

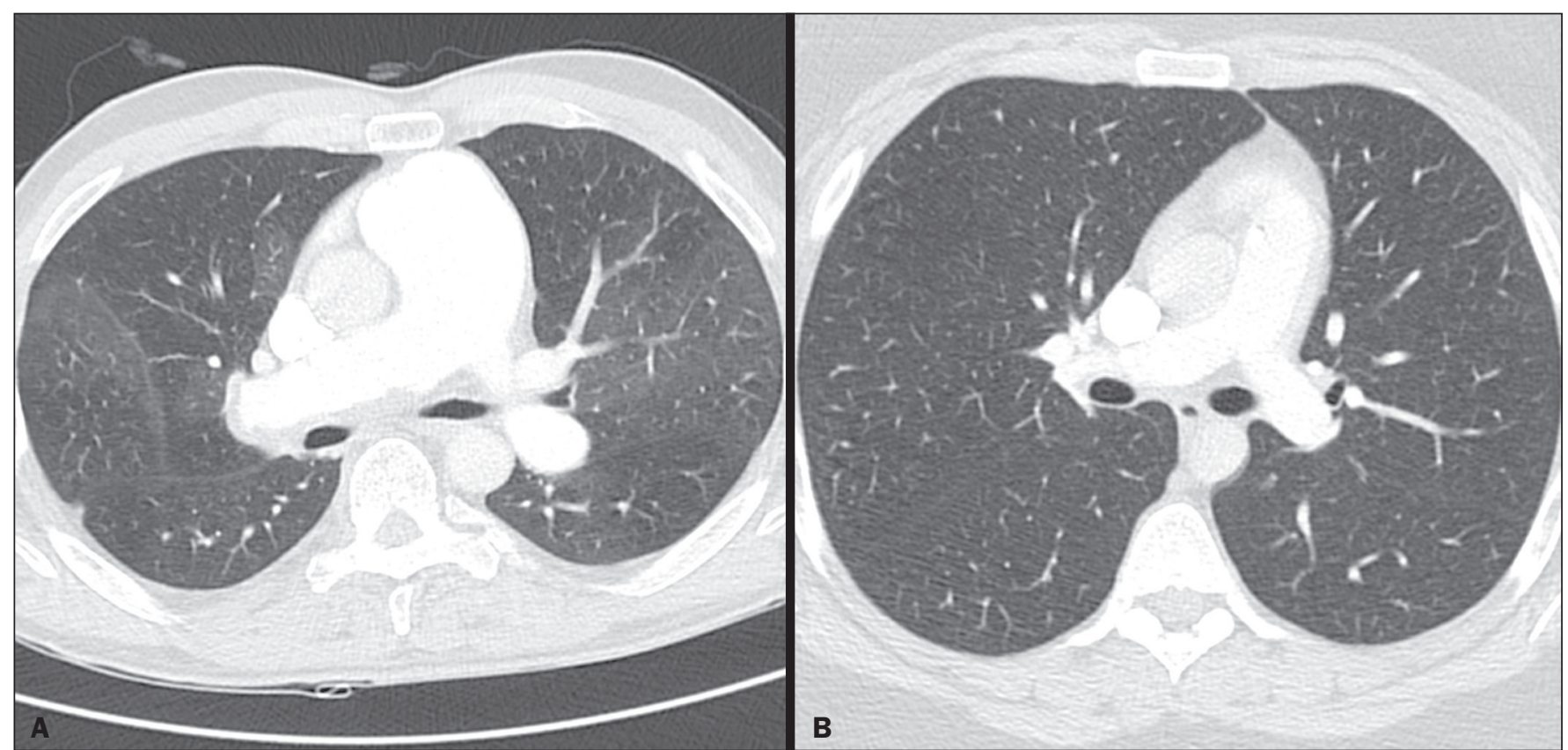

Figure 3. Axial CT images showing the difference in pulmonary attenuation between a patient with $\mathrm{PH}(\mathbf{A})$ and a patient of the control group (B). In $\mathbf{A}$, we can observe areas of low attenuation (oligemia) in the lung parenchyma of a patient with $\mathrm{PH}$, with a quantitative value of p10 of lung density of $-873 \mathrm{HU}$, as obtained by the Yacta program. The image in B shows homogeneous attenuation of the lung parenchyma of a patient of the control group ( $p 10:-760 \mathrm{HU}$ ).

Table 2-Parameters of the automated quantitative analysis performed on CTA images of PH patients and control patients, considering the lobar distribution of vessels.

\begin{tabular}{lccccc}
\hline Group & RUL vessels $\left(\mathrm{cm}^{3}\right)$ & LUL vessels $\left(\mathrm{cm}^{3}\right)$ & RUL/RLL vascular volume ratio & LUL/LLL vascular volume ratio & ULs/LLs vascular volume ratio \\
\hline Control & $13.3 \pm 5.8$ & $13.3 \pm 5.1$ & $0.5472 \pm 0.1889$ & $0.5712 \pm 0.2412$ & $0.5436 \pm 0.1529$ \\
PH & $18.5 \pm 9.3 *$ & $16.5 \pm 8.3$ & $1.0825 \pm 1.0992^{*}$ & $2.2274 \pm 5.1819 *$ & $1.1731 \pm 1.0915 *$ \\
\hline
\end{tabular}

RUL, right upper lobe; LUL, left upper lobe; RLL, right lower lobe; LLL, left lower lobe; ULs = upper lobes; LLs, lower lobes * Statistically different in comparison with the control group $(p<0,05)$.

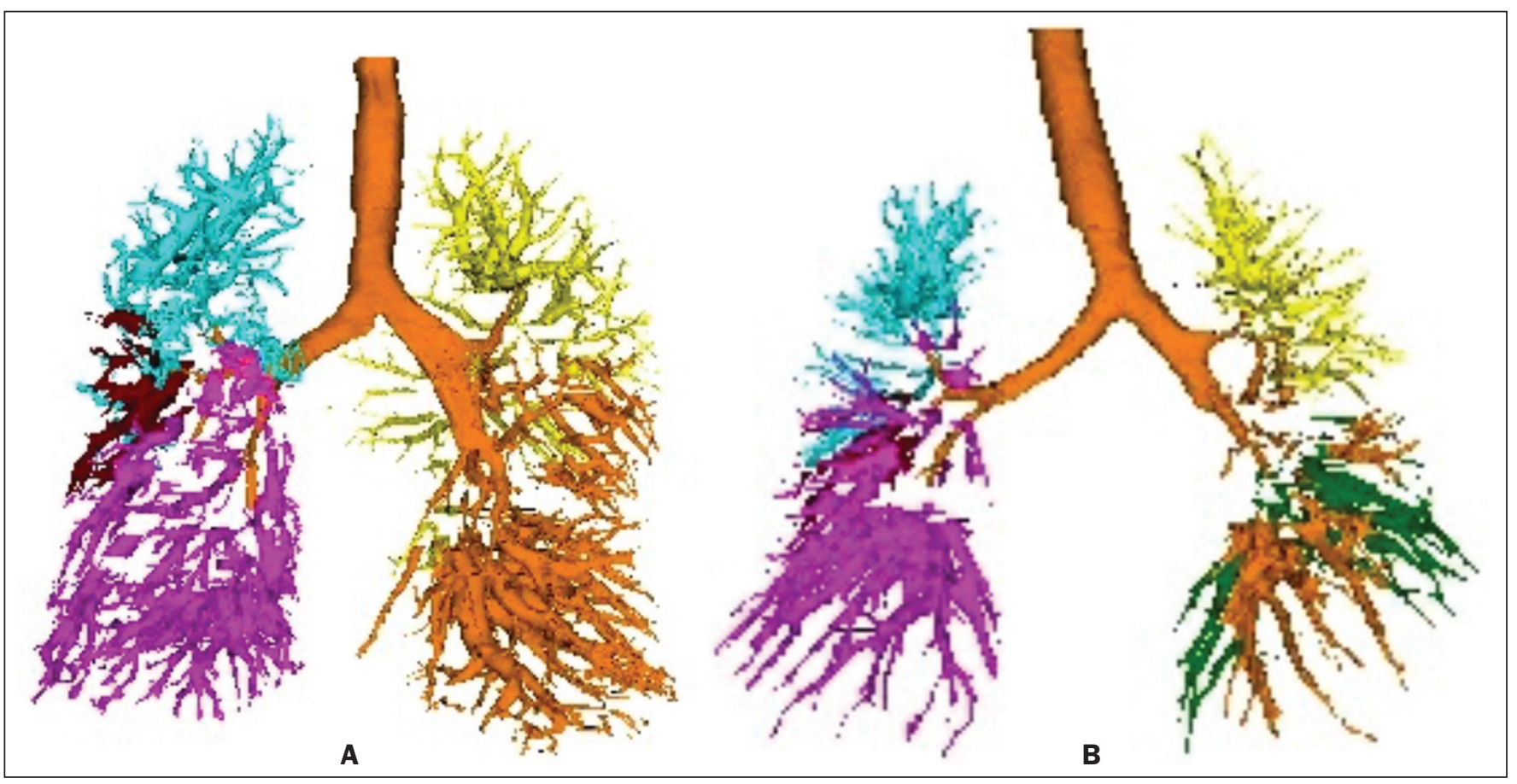

Figure 4. Three-dimensional reconstruction of the pulmonary vasculature by the Yacta automated program. The image in $\mathbf{A}$ shows the relatively greater volume of the pulmonary vasculature in the upper lobes than in the lower lobes in a patient with PH (ULs/LLs $=1.692)$, whereas the image in $\mathbf{B}$ shows a different picture in a patient of the control group (ULs/LLs $=0.6486)$. 


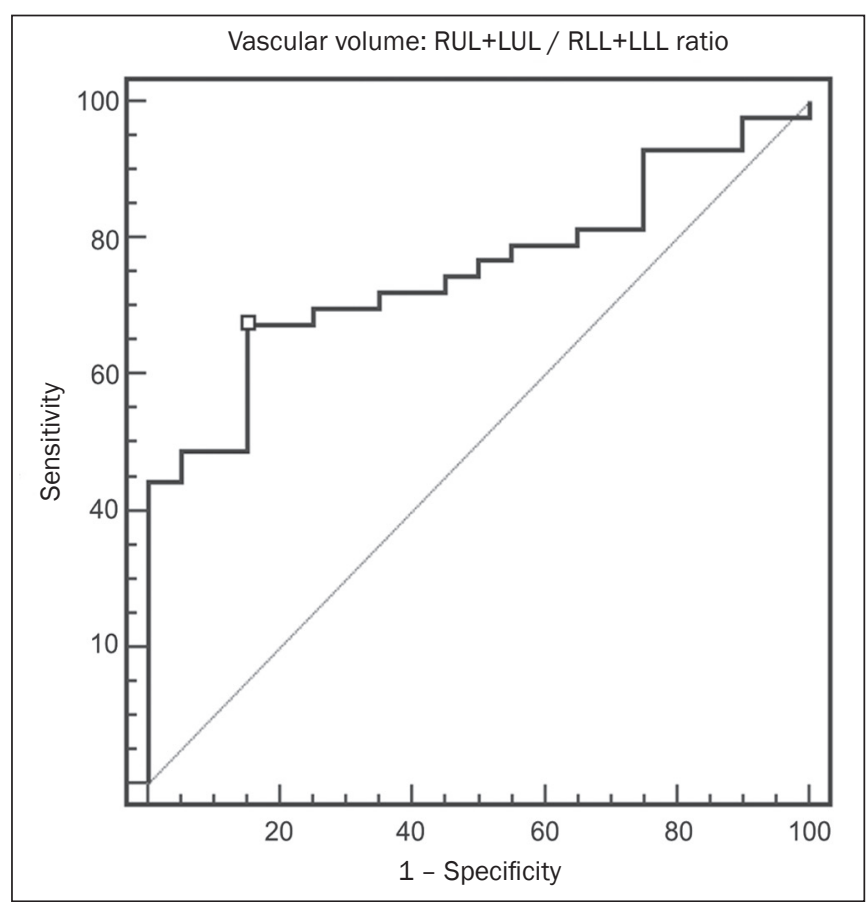

Figure 5. ROC curve for the quantitative CT measurement of the ULS/LLs ratio.

We identified one isolated case of pulmonary trunk dilatation in a patient in the control group.

\section{DISCUSSION}

In this study, the quantitative analysis of the CTA images of $\mathrm{PH}$ patients was performed using a fully automated program. The volume of the RUL vessels and the ULs/LLs ratio were higher in the $\mathrm{PH}$ patients than in the control patients. We infer that this finding probably represents the redistribution of the pulmonary vasculature, which pathologically indicates an increase in pulmonary vascular resistance. We also found that the p10 values for the mean density of the lung parenchyma were lower in the PH patients. This finding is likely representative of the presence of areas of low attenuation, indicating oligemia related to the pulmonary vascular disease. These quantitative measures, obtained in CTA examinations routinely used in the clinical evaluation of $\mathrm{PH}$ patients, show potential as objective, reproducible tool for the diagnosis, prognosis, and follow-up of patients with pulmonary vascular disease.

Despite all of the advances in imaging, the most widely used measure for the investigation of suspected $\mathrm{PH}$ is the diameter of the pulmonary trunk and its relationship with the ascending aorta measured in the $\mathrm{CT}^{(14,15)}$. However, some studies ${ }^{(16,17)}$ have questioned the specificity of the most commonly proposed pulmonary trunk diameter cut-off value, which is $29 \mathrm{~mm}^{(14-21)}$. It should be borne in mind that normal pulmonary trunk diameters are frequently found in cases of mild $\mathrm{PH}$, and a normal value therefore does not rule out the diagnosis. The diameter of the pulmonary artery relative to that of the ascending aorta at the same level has been suggested as a more specific measure in moderate and severe cases of $\mathrm{PH}^{(15)}$. Dilatation and tortuosity of the segmental pulmonary arteries (with a diameter 1.25 times that of the adjacent bronchus) in at least three lobes, in the absence of significant lung parenchymal disease, accompanied by dilatation of the pulmonary artery trunk, has also been described as a finding with high specificity ${ }^{(22)}$.

The technological evolution of CT devices and computer analysis programs allowed the development of objective, quantitative tools for analysis of the lung parenchyma (in cases of emphysema or fibrosis), the airways (in cases of chronic obstructive pulmonary disease, asthma, or cystic fibrosis), and, more recently, the pulmonary vessels. Some studies, such as that conducted by Ando et al. ${ }^{(23)}$, have demonstrated the potential of quantitative evaluation of the pulmonary vasculature for the detection of the effect of treatment with vasodilators in patients with chronic obstructive pulmonary disease and PH.

In this study, the quantitative parameter obtained in CT images with the greatest statistical significance was the ULs/LLs ratio, which was higher in the $\mathrm{PH}$ patients. We infer that this finding likely represents redistribution of the vasculature and an increase in pulmonary vascular resistance. The pulmonary vascular bed is a system of low resistance, and, when in the upright position, vessels supplying the upper lobes are smaller and fewer in comparison with those in the lung base ${ }^{(24)}$. In the supine position this difference tends to disappear, and the evaluation of the pulmonary vasculature has traditionally been given little weight in CT examinations. Our study demonstrates, in an objective way, that alteration of the pulmonary vasculature in patients with $\mathrm{PH}$ can be appreciated even when the examination is performed with the patient in the supine position.

Another interesting finding of this study was the difference between the $\mathrm{PH}$ and control patients in the p10 value for mean pulmonary density. The p10 value is a relative measure that is related to heterogeneity of the lung parenchyma and the presence of areas of low attenuation. A similar measure is that of the 15 th percentile of pulmonary densities, suggested, for example, for the characterization of pulmonary emphysema as an alternative to the most widely used threshold of $-950 \mathrm{HU}^{(25-27)}$. Although mosaic attenuation is an isolated finding with little specificity in the context of pulmonary vascular diseases, it is known that the pathological areas are those of low attenuation, which represent focal hypoperfusion of the parenchyma, associated with vascular oligemia ${ }^{(25,28)}$. We infer that the difference in the p10 values found in this study represents the presence of such areas of low attenuation in the lung parenchyma, associated with hypoperfusion/ oligemia. Therefore, the quantification of those areas also has potential in the imaging characterization of pulmonary vascular disease. 
This study has limitations. Although the ULs/LLs ratio differentiated the PH patients from the control patients, we did not find a good correlation between the ULs/LLs ratio and the mPAP measurements. One possible explanation for this is that our group of $\mathrm{PH}$ patients was heterogeneous, with a predominance of individuals in subgroups 1 and 4. It is possible that individualized studies of each of the PH subgroups would produce different results, given that the subgroups differ in terms of the pathophysiological mechanism underlying the development of $\mathrm{PH}$ and the clinical course of the disease. The fact that the CTA and the RHC examinations were performed on different dates might also have contributed to this limitation. In addition, not all RHC examinations were performed at the same facility and with the same equipment. Despite the advanced algorithm applied by the automated program, in approximately one third of the cases there were problems related to the automated lobar segmentation, mainly in terms of the identification of the middle lobe and the lingula. In such cases, those segments were incorporated into the upper lobes or the lobar evaluation was not included in the statistical analysis, only the analysis of the right and left lungs being maintained. We cannot unequivocally rule out the possibility that subjects in the control group had undiagnosed underlying cardiac or lung disease at the time of evaluation, especially because none of those patients underwent RHC. Finally, in our study, it was not possible to index the quantitative values obtained for weight and height, because the relevant data were missing from some medical records, especially those of the control patients. Indexing those values could have increased the accuracy of the comparative analysis between the groups ${ }^{(29)}$.

\section{CONCLUSION}

Quantitative analysis of the pulmonary vasculature and of attenuation of the lung parenchyma seen on CTA can provide objective data on $\mathrm{PH}$ and potentially on other pulmonary vascular diseases. These quantitative measures obtained automatically in examinations already used in the clinical routine of patient evaluation have potential as an objective, reproducible tool for the diagnostic evaluation, grading, and follow-up of patients with $\mathrm{PH}$ or other diseases that affect the pulmonary vasculature.

\section{REFERENCES}

1. Galiè N, Hoeper MM, Humbert M, et al. Guidelines for the diagnosis and treatment of pulmonary hypertension: the Task Force for the Diagnosis and Treatment of Pulmonary Hypertension of the European Society of Cardiology (ESC) and the European Respiratory Society (ERS), endorsed by the International Society of Heart and Lung Transplantation (ISHLT). Eur Heart J. 2009;30:2493-537.

2. Galiè N, Hoeper MM, Humbert M, et al. Guidelines for the diagnosis and treatment of pulmonary hypertension. Eur Respir J. 2009;34:1219-63.

3. Simonneau G, Robbins IM, Beghetti M, et al. Updated clinical classification of pulmonary hypertension. J Am Coll Cardiol. 2009;54( 1 Suppl):S43-54.
4. Hoeper MM, Lee SH, Voswinckel R, et al. Complications of right heart catheterization procedures in patients with pulmonary hypertension in experienced centers. J Am Coll Cardiol. 2006;48:254652.

5. Okajima Y, Ohno Y, Washko GR, et al. Assessment of pulmonary hypertension: what CT and MRI can provide. Acad Radiol. $2011 ; 18: 437-53$.

6. Stevens GR, Fida N, Sanz J. Computed tomography and cardiac magnetic resonance imaging in pulmonary hypertension. Prog Cardiovasc Dis. 2012;55:161-71.

7. Barfett JJ, Fierstra J, Mikulis DJ, et al. Blood velocity calculated from volumetric dynamic computed tomography angiography. Invest Radiol. 2010;45:778-81.

8. Pienn M, Kovacs G, Tscherner M, et al. Non-invasive determination of pulmonary hypertension with dynamic contrast-enhanced computed tomography: a pilot study. Eur Radiol. 2014;24:668-76.

9. Goldin JG. Computed tomography as a biomarker in clinical trials imaging. J Thorac Imaging. 2013;28:291-7.

10. Heussel CP, Herth FJ, Kappes J, et al. Fully automatic quantitative assessment of emphysema in computed tomography: comparison with pulmonary function testing and normal values. Eur Radiol. 2009; 19:2391-402.

11. Wielpütz MO, Eichinger M, Weinheimer O, et al. Automatic airway analysis on multidetector computed tomography in cystic fibrosis: correlation with pulmonary function testing. J Thorac Imaging. 2013;28:104-13.

12. Achenbach T, Weinheimer O, Buschsieweke C, et al. Fully automatic detection and quantification of emphysema on thin section MD-CT of the chest by a new and dedicated software. Rofo. 2004; 176:1409-15.

13. Newell JD Jr, Hogg JC, Snider GL. Report of a workshop: quantitative computed tomography scanning in longitudinal studies of emphysema. Eur Respir J. 2004;23:769-75.

14. Kuriyama K, Gamsu G, Stern RG, et al. CT-determined pulmonary artery diameters in predicting pulmonary hypertension. Invest Radiol. 1984;19:16-22.

15. Ng CS, Wells AU, Padley SP. A CT sign of chronic pulmonary arterial hypertension: the ratio of main pulmonary artery to aortic diameter. J Thorac Imaging. 1999;14:270-8.

16. Mahammedi A, Oshmyansky A, Hassoun PM, et al. Pulmonary artery measurements in pulmonary hypertension: the role of computed tomography. J Thorac Imaging. 2013;28:96-103.

17. Corson N, Armato SG 3rd, Labby ZE, et al. CT-based pulmonary artery measurements for the assessment of pulmonary hypertension. Acad Radiol. 2014;21:523-30.

18. Zisman DA, Karlamangla AS, Ross DJ, et al. High-resolution chest CT findings do not predict the presence of pulmonary hypertension in advanced idiopathic pulmonary fibrosis. Chest. 2007;132:773-9.

19. Alhamad EH, Al-Boukai AA, Al-Kassimi FA, et al. Prediction of pulmonary hypertension in patients with or without interstitial lung disease: reliability of CT findings. Radiology. 2011;260:87583.

20. Frazier AA, Galvin JR, Franks TJ, et al. From the archives of the AFIP: pulmonary vasculature: hypertension and infarction. Radiographics. 2000;20:491-524; quiz 530-2.

21. Peña E, Dennie C, Veinot J, et al. Pulmonary hypertension: how the radiologist can help. Radiographics. 2012;32:9-32.

22. Tan RT, Kuzo R, Goodman LR, et al. Utility of CT scan evaluation for predicting pulmonary hypertension in patients with parenchymal lung disease. Medical College of Wisconsin Lung Transplant Group. Chest. 1998;113:1250-6.

23. Ando K, Kuraishi H, Nagaoka T, et al. Potential role of CT metrics in chronic obstructive pulmonary disease with pulmonary hypertension. Lung. 2015;193:911-8.

24. Ravin CE. Radiographic analysis of pulmonary vascular distribution: a review. Bull N Y Acad Med. 1983;59:728-43. 
25. Sherrick AD, Swensen SJ, Hartman TE. Mosaic pattern of lung attenuation on CT scans: frequency among patients with pulmonary artery hypertension of different causes. AJR Am J Roentgenol. 1997;169:79-82.

26. Lim HJ, Weinheimer O, Wielpütz MO, et al. Fully automated pulmonary lobar segmentation: influence of different prototype software programs onto quantitative evaluation of chronic obstructive lung disease. PLoS One. 2016;11:e0151498.

27. Wielpütz MO, Weinheimer O, Eichinger M, et al. Pulmonary em- physema in cystic fibrosis detected by densitometry on chest multidetector computed tomography. PLoS One. 2013;8:e73142.

28. King MA, Bergin CJ, Yeung DW, et al. Chronic pulmonary thromboembolism: detection of regional hypoperfusion with CT. Radiology. 1994;191:359-63.

29. Schölzel BE, Post MC, Dymarkowski S, et al. Prediction of outcome after PEA in chronic thromboembolic pulmonary hypertension using indexed pulmonary artery diameter. Eur Respir J. 2014;43:909-12. 